Vladimír TLACH ${ }^{1}$, Vladimír STENCHLÁK², Milan SÁGA Jr. ${ }^{3}$

Supervisor: Ivan KURIC ${ }^{4}$

DOI: https://doi.org/10.53052/9788366249837.24

\title{
MOŻLIWOŚCI MONITOROWANIA ROBOTÓW PRZEMYSŁOWYCH POPRZEZ SYSTEM RENISHAW BALLBAR
}

\begin{abstract}
Streszczenie: W artykule omówiono możliwości wykorzystania Renishaw Ballbar QC20-W do monitorowania stanu robotów przemysłowych. System Renishaw Ballbar jest standardowym narzędziem przeznaczonym do diagnostyki i monitorowania obrabiarek CNC. Jego zastosowanie w robotach przemysłowych wynika z doświadczeń Katedry Automatyki i Systemów Produkcyjnych Wydziału Mechanicznego Uniwersytetu Żylińskiego oraz innych instytutów badawczych. W artykule przedstawiono metodykę monitorowania robotów przemysłowych opartą na przetwarzaniu danych pomiarowych z wykorzystaniem szybkiej transformacji Fouriera. W artykule zawarto również rekomendacje dotyczące wdrożenia proponowanego systemu w praktyce.
\end{abstract}

Słowa kluczowe: Robot przemysłowy, Renishaw Ballbar QC20-W, Monitoring

\section{POSSIBILITIES OF INDUSTRIAL ROBOT MONITORING BY RENISHAW BALLBAR SYSTEM}

Summary: The paper discusses the possibility of using Renishaw Ballbar QC20-W to monitor the condition of industrial robots. Renishaw Ballbar system is a standard tool designed for diagnostics and monitoring of $\mathrm{CNC}$ machine tools. Its use for industrial robots results from the experiences at the Department of Automation and Production Systems, Faculty of Mechanical Engineering, University of Zilina and other research institutes. The paper presents a methodology for monitoring industrial robots based on the processing of measured data utilizing the fast Fourier transform. The paper also contains recommendations for the implementation of the proposed system into practice.

Keywords: Industrial Robot, Renishaw Ballbar QC20-W, Monitoring

\footnotetext{
${ }^{1}$ University of Žilina, Faculty of Mechanical Engineering, Department of Automation and Production Systems, researcher, vladimir.tlach@fstroj.uniza.sk

${ }^{2}$ University of Žilina, Faculty of Mechanical Engineering, Department of Automation and Production Systems, PhD student, vladimir.stenchlak@fstroj.uniza.sk

${ }^{3}$ University of Žilina, Faculty of Mechanical Engineering, Department of Automation and Production Systems, PhD student, milan.saga2@fstroj.uniza.sk

${ }^{4}$ prof. Dr. Ing., University of Žilina, Faculty of Mechanical Engineering, Department of Automation and Production Systems, ivan.kuric@fstroj.uniza.sk
} 


\section{Introduction}

Industrial robots are widely used in various industries. One of the current trends is the replacement of single-purpose machines or similar devices by industrial robots. [1] Specific areas of application of industrial robots include, for example, precise assembly processes, machining of complex-shaped surfaces, checking the dimensions of the manufactured parts or objects using 3D scanning or measuring probes, and much more.

In the process of improving the competitiveness of a company, it is also essential to ensure the sufficiency of the performance parameters of machinery, including industrial robots. Using an industrial robot in the mentioned inspection applications, precision assembly or machining tasks, it is not only the selection of the robot with the optimal properties but also the monitoring of any change in these properties. In such a case, there is a requirement for regular measurement of an industrial robot to monitor its technical condition. With a sufficient amount of collected data and evaluation of trends of changes in diagnostic quantities, it is possible to prevent robot failure, production of nonconforming products and prevention of production failure or shortage. Various measuring devices and corresponding measurement methods are used in technical publications to measure industrial robots. Many of them, however, represent a complex measurement process that is intended for laboratory conditions rather than real production. Another factor discouraging from implementation may be the high cost of the measuring device necessary. Increasingly, measuring devices primarily designed for a different purpose such as to assess the condition of CNC machine tools are also used. [2, 3] Such devices include the Renishaw Ballbar QC20-W or the Renishaw XL-80 laser interferometer.

If the condition of an industrial robot is to be based on the measurement of its properties and applied in a real production process, the measurement process itself must meet several requirements. One of them is the ability to measure in the shortest time possible and in the simplest way possible. Another requirement is the evaluation of the measured data to obtain relevant information sufficiently characterizing the technical condition of the industrial robot. The present article deals with the option to use Renishaw Ballbar QC20-W for industrial robot condition monitoring. The conclusions are based on the results of measurements with the particular measuring device, carried out on Department of Automation and Production Systems. [4, 5] Renishaw Ballbar system is a standard tool designed to diagnose and monitor CNC machine tools while meeting the stated requirement of simplicity and speed of measurement.

\section{Basis of experiments}

Individual experiments, the results of which serve as a basis for the conclusions of this article, were performed on four Fanuc industrial robots. Specifically, the LR Mate 200iC (E31806), the LR Mate 200iD (E117096), the LR Mate 200iD / 7L (E101661, E109256). A repeatability value of $\pm 0.02 \mathrm{~mm}$ makes these robots ideal for use in precise applications where monitoring and diagnostics are most relevant. 
The Renishaw Ballbar QC20-W measuring assembly used (Figure 1) consists of a precise linear sensor to measure the variation in the distance between a pair of precisely ground steel balls located at its ends. They fit into two magnetic cups. One is located on the center mount that is magnetically clamped on the table and represents a fixed point of rotation when performing circular paths. The second magnetic tool cup is clamped on the end of the robot's arm using a connecting flange. The flange intends to ensure the coaxiality of the robot's joint J6 and the axis of the tool of the magnetic cup, as well as the repeatability of the clamping on the end of the robot's arm. Consequently, the measurement process itself is based on collecting a set of radius deviations during circular paths of the magnetic tool cup around a fixed pivot point represented by the center mount. [6,7]

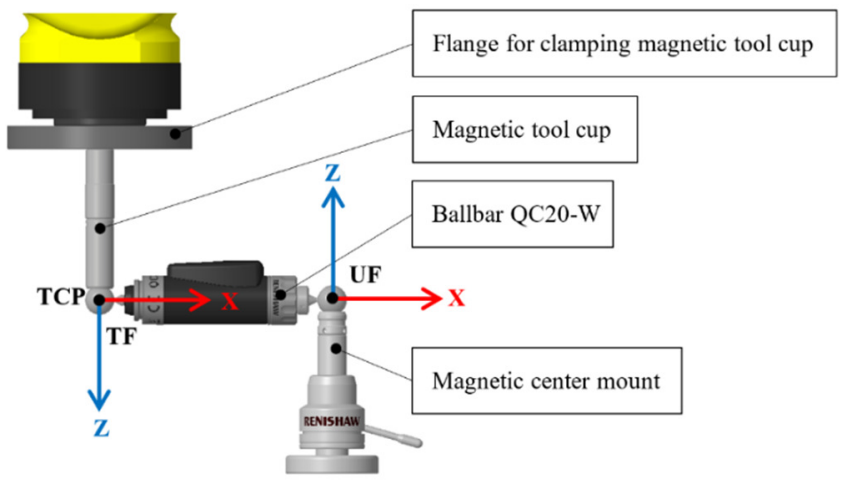

Figure 1. Measuring assembly and location of coordinate systems

The robot control program was created considering that the center of the circle of a given radius is at the beginning of the user coordinate system (UF) defined against the WCS (World Coordinate System, in the case of Fanuc robots it is a fixed coordinate system defined by the manufacturer). Such a method allows changing the location of the circular path by changing the position of the user coordinate system in the robot workspace. This makes the programs universal to some extent because they can be used not only on any Fanuc robot but also on any part of the robot's workspace. The relative position and orientation of the user and tool coordinate system (TF) used in all experiments performed is shown in Figure 1.

\section{Realized experiments}

Within the Renishaw Ballbar experiments carried out at the Department of Automation and Production Systems, several series of measurements were carried out with the primary aim to verify the possibility of using the system to monitor the condition of an industrial robot. Individual measurements can be divided into two main groups:

1. determination of measurement conditions and method of evaluation of measured data,

2. verification of the relationship between the shape of the recorded circular path and the calibration of the robot. 


\subsection{Measurement conditions and data evaluation method}

The sole purpose of this group of measurements was to compare two methods of circular path formation. The first method involves creating a circle using standard programming commands, such as joining two semicircles. For a smooth transition between the two semicircles, the CNT100 parameter, representing the most significant bypass of the programmed point, was selected. In the latter method, the circular path is formed as a polygon, representing the most accurate approximation of the desired circle. Based on the results of the experiments, there has been formed a conclusion on the mutual equivalence of the two methods of circular path formation. However, creating a circular path using two semicircles is a more natural and faster way to prepare a control program. It is not necessary to perform a tedious calculation of hundreds of coordinates of polygon vertices and then generate a control program for the robot. [5] This method was used in all other experiments.

In addition to the conclusion above concerning the methods of circular path formation, the value of the robot's TCP point velocity during the measurement was determined. This speed represents the value of $55.33 \mathrm{~mm} \cdot \mathrm{s}^{-1}$, entered in the robot control program and corresponds to a value of $3320 \mathrm{~mm} \cdot \mathrm{min}^{-1}$ for the Ballbar 20 program. At this speed value, the measurement process itself consists of describing two clockwise circular paths $(\mathrm{CW})$ and two circular paths in the opposite direction $(\mathrm{CCW})$, which lasts 53 seconds. The total time, including the preparation of the measurement, depends on the level to what extent are required operations automated and carried out.

Furthermore, a method of processing the measured data was proposed, allowing us to analyze them in more detail. The method uses fast Fourier transformation (FFT) to decompose the recorded circular profile into individual harmonic components. In Figure 2, graphical processing of the first ten harmonic components of the profile are displayed. The first ten harmonics are commonly used to analyze circularity. In the graph, the second harmonic component, representing ovality, is dominant. The amplitude of the first harmonic component is adjusted to zero as it represents eccentricity and can be considered a measurement error.

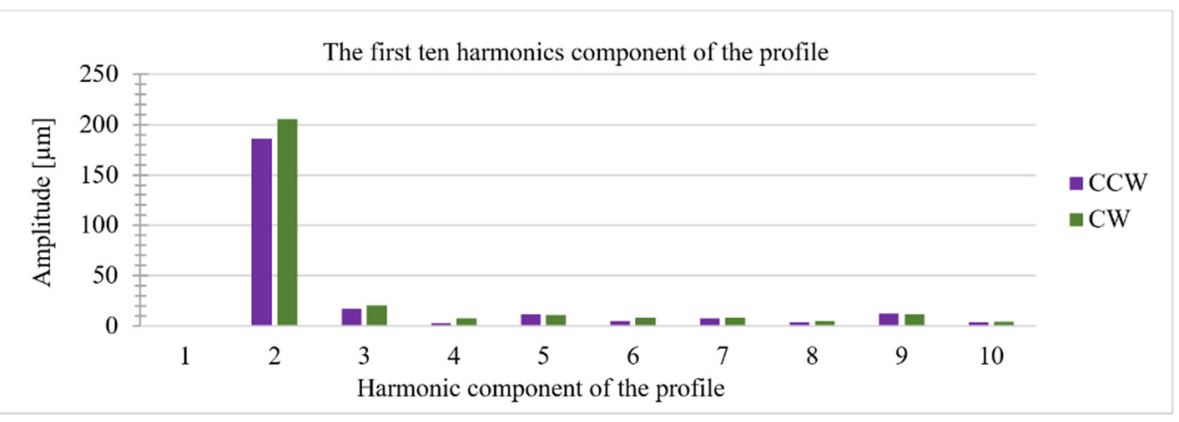

Figure 2. FFT analysis

The magnitude of the amplitude values of the second harmonic component is associated with a considerable deformation of the recorded circular profile. A polar graph from this particular measurement is shown in Figure 3a. Further, Figure 3b shows a polar graph formed by the reverse composition of the first ten harmonic 
components of the profile. Polar graphs created from these modified values can, in most cases, be easier to compare.
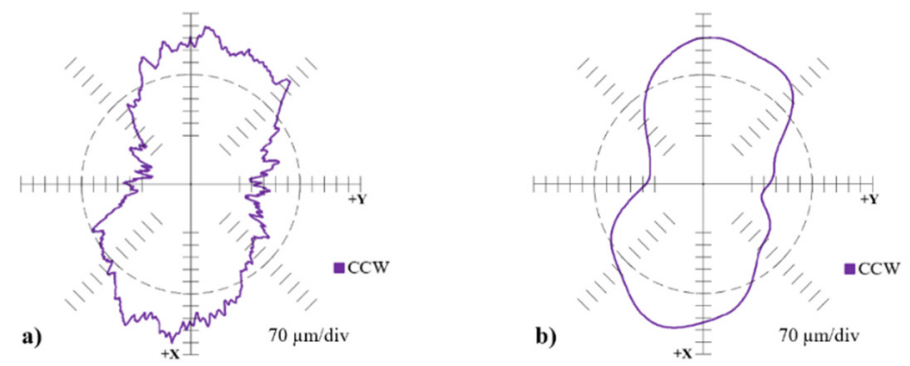

Figure 3. Circular path profile recorded by the Renishaw Ballbar system (a) and created by the reverse composition of the first ten harmonic components of the profile (b)

\subsection{Verification of the relationship between the shape of the recorded circular path and the robot's calibration}

The experiments within this group of measurements were aimed at verifying the hypothesis of correlation of the circular path deformation observed in measurements with the Renishaw Ballbar system and the accuracy of the calibration. Calibration in this context is to establish the right relationship between the actual position of the robot arm and the information from the position sensors in its individual joints. This relationship is created by correctly adjusting the zero positions of each robot's joint. [8]

Two sets of measurements were performed on the Fanuc LR Mate 200iC robot, located at the Department of Automation and Production Systems. This robot was chosen not only because of availability at the department but also because of the less accurate calibration method used so far. [4] The first set of measurements was carried out with an inaccurate calibration of the robot. The shape of the circular path obtained is shown in Figure $4 \mathrm{a}$, where the considerable deformation can be seen. Such deformation, irrespective of the connection to the calibration process, indicates a deteriorated technical condition of the robot, which will most likely affect line accuracy. In addition to evaluating the measurements based on the polar graph, the mean value of the second harmonic component of the profile, representing ovality, was calculated from five repeated measurements (see Table 1). The calculation was carried out as mentioned above, consisting of decomposition of the circular profile into harmonic components utilizing fast Fourier transformation.

After refining the robot calibration, the measurement was repeated under the same conditions and at the same place in the robot workspace. A more accurate calibration manifests, in the obtained polar graph, mainly as a reduction of the circular path deformation, see Figure $4 \mathrm{~b}$. As with the first series of measurements, the average value of the second harmonic component of the profile was calculated. Comparing these values for both series of measurements is possible in Table 1. shows that after the calibration of the robot, the calculated values are almost three times lower than before the calibration. 

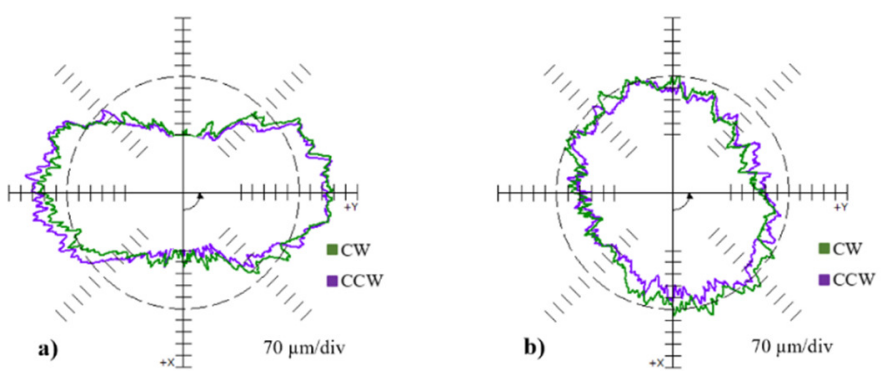

Picture 4. Circular path profile before (a) and after $(b)$ robot calibration

Table 1. Comparison of the average amplitude values of the second harmonic component of the profile

\begin{tabular}{|c|c|c|}
\hline & CCW $[\mathrm{mm}]^{*}$ & CW [mm]* \\
\hline Before calibration & 181.2 & 208.6 \\
\hline After calibration & 72.6 & 50.4 \\
\hline
\end{tabular}

*CCW: measurement upstream control clockwise; CW: measurement clockwise.

An equally positive effect of refinement of the calibration was also observed in linear path straightness measurements using a Renishaw XL-80 laser interferometer. Experiments performed confirmed the effect of robot calibration accuracy on circular path deformation observed in the Renishaw Ballbar QC20-W measurement results. At the same time, the presented results create space for the use of the equipment in the process of industrial robots monitoring. [4] In such a case, the method of assessing the condition of an industrial robot is based on the assumption that if the periodically repeated measurements are taken at the same location each time and the technical condition of the robot does not change, then the shape of the circular path remains constant.

\section{Monitoring of the industrial robots' condition}

As indicated at the end of the previous chapter, the proposed methodology for monitoring an industrial robot using the Renishaw Ballbar system is based on the comparison. In this context, the first step is, therefore, to carry out initial measurements that provide reference values from the period when the robot is in the correct technical condition. Subsequently, the results from periodically repeated measurements are analyzed as comparisons with the reference values, and on the basis of the deviations, it is possible to evaluate the condition of the given robot.

The proposed methodology considers the recording of measurements using standard Ballbar 20 software, which is designed for measurement with the Renishaw Ballbar system. Subsequently, the recorded data is processed by a circular profile decomposition process using a fast Fourier transformation. This method of data processing has proven successful in our experiments and is also described in this paper. In this context, there are two possible forms of reference data based on which, the status of an industrial robot can be evaluated. The first form is the reference profile shown in the polar graph. The second option is to use a particular value of one of the 
harmonic components of the profile, for example, it may be the second harmonic component of the profile, representing ovality.

If the monitoring process is to be based on a reference profile, the following five points indicate the procedure to create it from initial repeated measurements:

1. Calculation of the first ten harmonic components of the profile for each of the repeated measurements using fast Fourier transformation.

2. Zeroing the first harmonic component of the profile, eliminating the eccentricity error.

3. Calculation of the average value for each of the harmonic components of the profile.

4. Reverse composition of the profile from the calculated mean values by inverse Fourier transformation.

5. Displaying of the profile, created in such a way, in the form of a polar graph, see Figure 5.

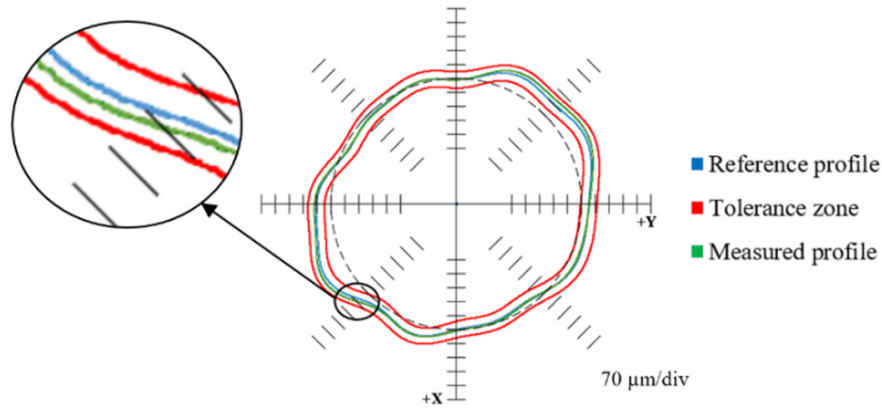

Figure 5. Polar graph with a reference profile for industrial robot status monitoring

In the polar graph (Figure 5), in addition to the reference profile, there are also two profiles representing the tolerance zone within which each repeated measurement carried out in the monitoring process will be considered. In order for the tolerance zone profiles to retain the same line as the reference profile, these profiles need only be created by changing the value of the zero harmonic component representing the base radius. Values for the tolerance zone can be determined, for example, as plus / minus three sample standard deviations from the average mean of the base radius.

In order to be able to evaluate it this way, every repeated measurement carried out as part of the monitoring of the industrial robot must be adequately processed. This means that if the reference profile was created by the reverse composition of the first ten harmonic components of the profile with limited eccentricity, then each measurement must also be processed in the very same way. Consequently, if the circular profile obtained as part of the monitoring is in the middle of the tolerance zone in the polar chart, then the status of the industrial robot can be assessed as unchanged. Conversely, if the circular profile is outside the tolerance zone, for example due to a change in its shape, it is necessary to look for a particular reason.

The second approach to monitoring industrial robots is to monitor only some of the harmonic components of the profile. It may be, for example, a second harmonic 
component representing ovality that is directly related to the shape of the recorded circular path. In this case, the procedure for obtaining the reference value is the same as for the reference profile, with the difference that the average values of the individual harmonic components do not form a polar graph. In the case of graphical processing, it is possible to start from the control chart intended for process control and management. That is, the graph shows the average value of some of the harmonic components, along with a tolerance zone formed, for example, as plus / minus three standard deviations from the mean value. According to statistical rule 3 sigma, then $99.73 \%$ of the values of all repeated measurements are located in such an interval. The diagram thus generated is shown in Figure 6. The evaluation of the status of an industrial robot is based on the monitoring of a specific value within the tolerance zone in the created diagram.

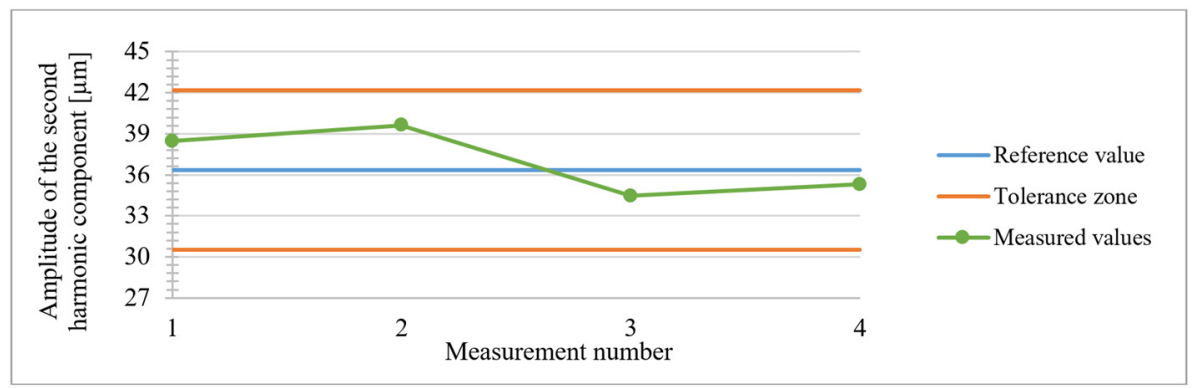

Figure 6. Diagram for monitoring the second harmonic component of the profile

\section{Requirements to the practical implementation of the measurements}

In connection with the issue of introducing the monitoring process into real production, it is necessary to consider placing the measuring apparatus in the workplace and also on the robot end's arm. All the experiments mentioned in this paper were carried out on industrial robots to be tested in a laboratory or robots before being deployed for real applications. Their common feature was the possibility of mounting a measuring flange, through which the mentioned magnetic cup was attached to the robot end's arm (see Figure 1). In the case of industrial robots in real production, it is not easy, and in most cases, it is not even possible to place the magnetic cup on an existing effector, or removing the effector and using the measuring flange.

Removing an existing effector can cause many issues. One of them is to introduce inaccuracies into robot movements due to manufacturing inaccuracies of the effector connecting flange or missing elements ensuring repeatability of the effector assembly. Likewise, in most cases of effectors, its disassembly requires the disconnection of electrical wires, pneumatic lines, etc. These steps would increase the time required to prepare the measurement. At the same time, after the measurement, it is necessary to check the correct assembly and connection of the effector. The realization of these operations and the time required for it is precluded by the requirement of simplicity and speed of measurement defined in the introduction. The only exception is when the robot is equipped with an automatic effector replacement system and the 
measuring flange is in the position of a separate effector. In manipulating effectors there is still the possibility of gripping the product with a magnetic cup into the fingers. In some cases, using a magnetic mount similar to the center pivot can be considered.

In any case, it is necessary to consider the location of the measuring apparatus during the design of the effector already. In this way, the abovementioned complications and actions due to disassembly of the effector are avoided. For measurements with Renishaw Ballbar QC20-W, only the M8 threaded hole is required to clamp the extender with the magnetic cup. Subsequent assembly of the measuring equipment in such a prepared place represents a time that could be considered as not the important factor.

In addition to adjustments related to the effector and clamping of the measuring apparatus, it is also important to select the measuring point in the robot workspace. Experiments performed with the Renishaw Ballbar system on industrial robots show different results when measured at different locations in the robot workspace. Therefore, all repeated measurements must take place at the same location within the robot workspace, in order to allow its proper evaluation. At the same time, the position should be chosen in those parts of the workspace in which the movement of the industrial robot is the greatest or in which it is important to monitor the technical condition of the robot. These are places where the emphasis is placed on the accuracy and repeatability of the robot. The same recommendation regarding the measuring point is also given in standard ISO 9283 [9] regarding the performance characteristics of industrial robots.

\section{Conclusion}

For monitoring and diagnostics of industrial robots under practical conditions, a measuring device that meets the requirements of simplicity and speed of measurement is required. Renishaw Ballbar system was chosen for experimental measurements carried out at the Department of Automation and Production Systems. This system has been designed and used to diagnose CNC machine tools and it is a very efficient tool due to its speed and simplicity of measurement. Based on previous experiments in the past, presented in this paper, the conditions of measurement and the system of evaluation of measured data were determined. These results form the basis not only for further experiments with the Renishaw Ballbar system, but mostly to design the monitoring methodology for industrial robots.

The proposed monitoring methodology is based on the assumption that if periodic measurements are always performed at the same location, within the working space of the robot and its technical condition does not change, then the shape of the circular path remains constant. For this purpose, reference data, characterizing the correct or required technical state of the industrial robot. Subsequently, the results obtained in the process of regularly performed measurements are compared with reference data, and the robot status can be evaluated based on variations. Two possible forms of reference data are presented in the present paper, both of which use fast Fourier transformation. In the first case, the reference data takes the form of a circular profile formed from the first ten harmonic components. The second form of reference data 
represents only a particular value of the harmonic component of the profile, which is used for comparison. It may be, for example, a second harmonic component representing ovality and at the same time characterizing the deformation of the measured circular profile.

The standard Ballbar 20 software was used to record the measurement results with Renishaw Ballbar QC20-W for all realized experiments. Subsequently, the measured data were extracted from the measurement file and further processed in Microsoft Excel using the NumXL analytics plug-in. The method of processing the measurement is a time-consuming process that does not in any way affect the measurement time itself. On the other hand, the measurement evaluation time must be as short as possible. In this case, there is room for further work in this field, related to the development of specialized software for automated processing and measurement evaluation.

\section{Acknowledgement}

This work has been supported by KEGA project No. 006ŽU-4/2019.

\section{REFERENCES}

1. Blum-Novotest, s.r.o.: Robotic measurement with BLUM BG60 probe [in Slovak]. Strojárstvo / Strojírenství, 21(2017)5, 111.

2. SLAMANI M., JOUBAIR A., BONEV IA.: Assessment of the positioning performance of an industrial robot. Industrial Robot: An International Journal, 39(2012)1, 57-68.

3. NUBIOLA A., SLAMANI M., BONEV IA.: A new method for measuring a large set of poses with a single telescoping ballbar. Precision Engineering, 37(2013)2, 451-460.

4. KURIC I., TLACH V., CÍSAR M., SÁGOVÁ Z., ZAJAČKO I.: Examination of industrial robot performance parameters utilizing machine tool diagnostic methods. International Journal of Advanced Robotic Systems, 17(2020)1, 1-11.

5. TLACH V., SÁGOVÁ Z., KURIC I.: Circular and quasi-circular paths for the industrial robots measuring with the Renishaw Ballbar QC20-W. MATEC Web of Conferences. EDP Sciences, 254(2019), 1-11.

6. JÓZWIK J., KURIC I., OSTROWSKI D., DZIEDZIC K.: Industrial robot accuracy testing with QC20-W Ballbar diagnostic system. Manufacturig Technology, 16(2016)3, 519-524.

7. MAJDA P.: The influence of geometric errors compensation of a CNC machine tool on the accuracy of movement with circular interpolation. Advances in Manufacturing Science and Technology, 36(2012)2, 59-67.

8. KARAN B., VUKOBRATOVIĆ M.: Calibration and accuracy of manipulation robot models-an overview. Mechanism and Machine Theory, 29(1994)3, 479_ 500 .

9. STN ISO 9283 Manipulating Industrial Robots - Performance criteria and related test methods, 1995. 